\title{
The Importance of Online Resources for Parents of Children with Special Needs in Hong Kong: South China's Experience Wilfred HS Wong ${ }^{1}$, Sophia L Li ${ }^{1}$, King-Wa Fu², Helen Tinsley ${ }^{1}$, Chun-Bong Chow ${ }^{1}$ and Patrick Ip ${ }^{1 *}$
}

${ }^{1}$ Department of Pediatrics and Adolescent Medicine, Li Ka Shing Faculty of Medicine, The University of Hong Kong, Hong Kong

${ }^{2}$ Journalism and Media Studies Centre, The University of Hong Kong, Hong Kong

\begin{abstract}
Background: Caring for children with special needs can be challenging and stressful for parents. Access to information and support is critical for parents to overcome these challenges. This study aims to study parental experiences and needs of searching and utilizing online information to support the care of their children with special needs.
\end{abstract}

Methods: Forty-nine participants were interviewed. All discussions were transcribed and examined using a thematic analysis method.

Results: Three main themes were identified, including information needs, experiences of obtaining and using information, and the advantages and challenges of searching and utilizing Internet information.

Conclusions: Availability of up-to-date information and emotional support is beneficial to Chinese parents of children with special needs. Although plenty of information can be accessed through the Internet, parents require eHealth literacy to use and interpret this online material. Conventional sources of information such as community groups remain important for those with low eHealth literacy.

Keywords: Chinese children; Special needs; Internet use; Information seeking; Parents; Digital divide

\section{Introduction}

Caring for children with special needs is very demanding for parents because the child's functioning in daily life is limited. Parents of children with special needs may experience poor psychological health $[1,2]$ from the stress of caregiving and from the lack of adequate information or support [3-10]. This stress may be further increased by the lack of available resources that address the parents' personal needs and their own aspirations [11]. Previous studies showed that adequate access to relevant information is critical to the care of children with special needs and the mental well-being of their parents. Above all, parents wanted reliable information on education, social and health care services and other community services available for their children $[12,13]$.

Comprehensive and timely information could help families caring for children with special needs to cope with the stresses involved in such an environment. Relevant resources could also be useful for promoting the mental well-being of the caregivers. The critical period just before and after confirmation of the child's condition is when the parents often experience a high level of insecurity and anxiety due to the lack of relevant information and medical knowledge $[14,15]$. Parents given access to the relevant information would become less despondent as they would have a better understanding of this medical condition and could learn about strategies to overcome the types of obstacles that are likely to occur [16]. Moreover, through this valuable information-seeking process, parents can build up related knowledge and skills, making them feel more confident in their role as a caregiver and thereby strengthening the parent-child bond [17]

The use of the Internet is constantly increasing and in this regard has now become an important tool for finding information on health matters. Its application can be considered as a powerful mobilization strategy for engaging various user groups. A distinct advantage of the Internet is the potential for enhanced outreach in providing eHealth services to the community. The Internet is thus increasingly recognized as a practical and cost-effective platform for health information delivery. It allows content to be updated instantly and inexpensively in comparison to the traditional media [18]. Discussions have suggested electronic dissemination of information has a lot of potential when compared to traditional media, especially in its message propagation speed and ability in audience reaching [19]. Parents and families can be benefited from computer-mediated social support, self-help, chat rooms and exchange of lay knowledge [20]. Parents can look for information on the internet about the health of their child and the management of this condition [21]. Besides conventional sources of information from professionals, friends and traditional media, more and more parents consider the Internet to be a major source of information about this condition [22]. Furthermore, parents can receive support and assistance from other parents in similar circumstances through online forums [23,24]. The mental well-being of parents of children with special needs could potentially be improved through the interactions and mutual support of other parents, especially with such easy access to the Internet [22]. Previous studies have shown that parent-to-parent support could exert a powerful stress-buffering effect [25].

The substantial variation in the eHealth literacy of parents is of great concern, because electronic health resources can only be useful if parents know how to use computers to search for relevant information. They also need to understand and put this information into the right context. Online information can be useful by supplementing expert advice, which is often too general to meet the parents' needs $[26,27]$. However, the level of an individual's eHealth literacy could lead to disparities in the ability to access health information and result in the

${ }^{*}$ Corresponding author: Patrick Ip, Department of Pediatrics and Adolescent Medicine, 1/F, New Clinical Building, Queen Mary Hospital, Hong Kong, Tel: (852) 28198501; Fax: (852) 2255 4089; E-mail: patricip@hku.hk

Received May 28, 2015; Accepted June 19, 2015; Published June 26, 2015

Citation: Wong HSW, Li SL, Fu K, Tinsley H, Chow C, et al. (2015) The Importance of Online Resources for Parents of Children with Special Needs in Hong Kong: South China's Experience. J Health Med Informat 6: 192. doi:10.4172/2157-7420.1000192

Copyright: (c) 2015 Wong HSW, et al. This is an open-access article distributed under the terms of the Creative Commons Attribution License, which permits unrestricted use, distribution, and reproduction in any medium, provided the original author and source are credited. 
emergence of a digital divide among parents [28]. While parents with high eHealth literacy could benefit from the comprehensive resources on the Internet, parents with low eHealth literacy could potentially be exposed to non-credible information and risk making inappropriate treatment decisions for their children [29].

During November 2006 to December 2007, the number of children under age 15 with disabilities in Hong Kong (excluding intellectual disability due to lack of data) was 13400 , which was about $1 \%$ of children in this age group [30]. However, the majority of the existing research on the importance and availability of online resources for parents of children with special needs has been conducted in western countries [31,32]. To date, no similar studies have been conducted in Hong Kong or South China. Through the perspectives of multiple stakeholders, this study aims to study parental experiences and needs of searching and utilizing online information to support the care of their children with special needs.

\section{Methods}

This qualitative study consisted of semi-structured focus group interviews. The focus group interview is a popular tool for health and community research and has several advantages over individual interviews [33]. The group dynamic is favorable for generating useful information and ideas, which participants may be reluctant to share during individual interviews [34]. Focus group interviews can be a time- and resource-saving way to explore complicated topics; for example, it can be used to understand and appreciate the participant's subjective experience [35].

\section{Participants}

Parents and professionals looking after children with special needs were invited to participate in the present study by referral from non-governmental organizations, special schools, parent groups, and medical experts in the relevant fields. A total of 59 participants (Chinese Hong Kong residents) agreed to take part in this study after being approached by phone and email, but, 10 of them (4 child advocators, 2 medical doctors, 1 social worker, and 3 educators) failed to show up on the day of their group interview. As a result there were 49 participants including 39 professionals in relevant fields and 10 family members of children with special needs ( 7 parents, 2 elder siblings of children with learning disability, and an aunt of a child with hearing loss). Among the seven parents, one had a child with visual disability, one had a child with hearing disability, three had children with physical disabilities, and the remaining two had children with mental disabilities. Four family members were also representatives of different non-government organizations serving children with mental disabilities, learning disabilities, hearing impairment and thalassemia respectively. All of them were included in the parent's focus group. All the professionals ( 6 child advocators, 8 medical doctors, 9 nurses and allied health professionals, 9 social workers, and 7 educators) had extensive experience in providing care and support for children with special needs. Characteristics and background of participants of different focus groups are listed in Table 1.

The professional participants were divided into five focus groups based on their expertise and nature of their work to facilitate discussion and identification of differences in attitudes and opinions among similar professions. Family members attended a separate focus group so that the viewpoints of the family members could be compared with that of the professionals. The focus groups, consisting of between six and ten participants, were conducted by two researchers, one was the moderator and the other was an observer. A protocol was developed to guide the focus group interviews (Appendix 1). The wording and syntax of the questions were slightly adjusted for each interview to allow the collection of in-depth viewpoints of the participants from different disciplines. All interviews and discussions were conducted in Chinese. General issues about the perceptions of participants were discussed in all the interviews. Based on the advice and suggestions of a panel of four expert professionals from pediatrics, education and social service sector, and two parent group representatives, relevant questions on their major concerns in day-to-day caring of children with special needs were developed. They included: (a) the experiences of parents in seeking general information related to the health and care of children with special needs (i.e., sources, accessibility, and subjective evaluation of relevant information), (b) the unmet needs of parents seeking essential information, (c) available services for parents in looking after children, (d) experiences of parents in seeking online information (i.e., the frequency of online search, what they searched for, and subjective evaluation of web-based resources), and (e) the value of the parents' online experiences on their daily living. At the end of each interview, unclear responses or issues were verified by asking the participants of the group for confirmation and clarification.

\section{Data analysis}

The audio recordings from the interview sessions and group discussions were transcribed into Chinese for data analysis [36]. An English copy of the transcript was also developed to facilitate the review process which involved English-speaking team members. A-priori themes were derived from the interview guide, which include a) information needs for caring of children with special needs, and b) experiences of obtaining and using information. Inductive themes were developed through thematic analysis, which was used to group together data with similar content. This process resulted in the formation of different information units [37]. A combination of broad-brush coding and fine-grained (line-by-line) coding was used to consolidate the information. By carefully analyzing each transcribed interview line by line, the researcher could identify areas of agreement and disagreement both within and between groups. A new theme was developed from the coding process, which were the advantages and challenges of searching and utilizing Internet information. The summary of themes and subthemes were detailed in the results section.

\section{Trustworthiness and reflexivity}

In order to ensure the internal consistency of the coding, one team member trained in adolescent health and qualitative research, who was native Chinese speaker and familiar with Hong Kong cultural context, was responsible for coding and data analysis. Other team members were kept informed of the progress of analysis throughout the process [38]. In order to minimize bias in interpretation/coding, a number of actions were taken to ensure the reflexivity of the findings. The participants were invited to review the content of the transcript and the analysis was carried out upon the accuracy and authenticity of the content of the transcript. The themes derived during the coding process were independently reviewed throughout the data analysis by research team members and external consultants. Disagreement was resolved by in-depth discussion and negotiated consensus. As a final step of the checking process and to ensure the findings were reliable, the themes/ constructs generated from this study were reviewed by members of the focus groups or people with similar work/life experiences. Through this rigorous procedure of checking and cross-checking, the trustworthiness of the constructs and their interpretation could be ascertained $[33,38]$. 


\begin{tabular}{|c|c|c|c|c|c|c|c|c|c|}
\hline & 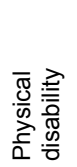 & 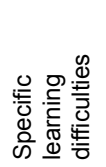 & 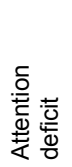 & 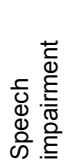 & 竞 & 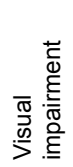 & 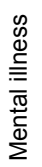 & 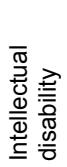 & 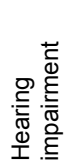 \\
\hline \multicolumn{10}{|l|}{$\begin{array}{l}\text { Focus group } \\
\text { (No. of participant)a }\end{array}$} \\
\hline Family (10) & 2 & 1 & 1 & - & 1 & 1 & 1 & 1 & 4 \\
\hline Child advocator (6) & 5 & 3 & 3 & 2 & 3 & 2 & 2 & 3 & 2 \\
\hline Medical doctor $(8)^{b}$ & 8 & 8 & 8 & 8 & 8 & 8 & 8 & 8 & 8 \\
\hline Nurse \& Allied health professional (9) & 4 & 3 & 4 & 3 & 4 & 2 & 4 & 2 & 3 \\
\hline Social worker (9) & 5 & 4 & 2 & 4 & 6 & 3 & 2 & 4 & 2 \\
\hline Educator (7) & 3 & 1 & 1 & 6 & 1 & 2 & 1 & 5 & 1 \\
\hline
\end{tabular}

aEach participant can be involved in more than one special need

${ }^{b}$ Each doctor has worked in various areas of special needs

Table 1: Focus group participants categorized by children's different types of special needs

\section{Ethics statement}

Written informed consent was directly obtained from all participants prior to their focus group session. The study and the consent procedure were approved by the Institutional Review Board of the University of Hong Kong and Hong Kong Hospital Authority (Hong Kong West Cluster).

\section{Results}

Data was analyzed according to three main themes: information needs for caring of children with special needs, experiences of obtaining and using information, and advantages and challenges of searching and utilizing Internet information. Sub-themes were derived from the qualitative data of the focus group interviews (Table 2) and supported by relevant quotations (Table 3 ).

\section{Information needs for caring of children with special needs}

Diagnosis, assessment and prognosis of child's medical condition: Access to appropriate information on health and medical care can help parents better understand their child's condition and treatment options, and direct them to available support in the community. In our study, parent participants perceived that they were more confident and capable of caring for their children with special needs when they had adequate knowledge about their child's physical and psychological conditions. Professionals also emphasized the importance and benefits of parents having adequate information about their child's condition. Parents' eagerness for information about their children's medical and developmental conditions was suggested by an occupation therapist (Table 3: quotation 1).

Medical rehabilitation and psychosocial health: Parent participants also elaborated on the importance of having access to information on the rehabilitation and management of their children. In particular, they mentioned about the lack of dental services for children with special needs. This has been identified as one of the key services from parents' perspective, however such have not mentioned in any of the professional groups (Table 3: quotation 2). In addition to the need for information concerning the child's medical conditions and care management, both parents and social workers also highlighted the need for information on the child's psychosocial health and development (Table 3: quotations 3 and 4).

Education services: Information on relevant education services was another major concern. Parents always looked for information on whether mainstream schools would enroll children with special needs, and whether there were sufficient facilities and resources in schools to support their children's needs (Table 3: quotation 5). Parents often encountered difficulties in finding education services for their children at older ages. They preferred to contact social workers directly for various special needs information. However, due to the insufficient facilities provided in Hong Kong, the waiting time for children in needs were often prolonged, which suggested by a social worker (Table 3: quotation 6).

Besides education provided at special schools, we found a general lacking of extra-curricular activities for children with special needs. Skills training during extra-curricular activities were considered important to promote development of children with special needs. From parents' perspective, seeing their children unable to study in mainstream schools, they would like to seek for alternatives, for example: extra-curricular activities that to enhance children's learning exposures (Table 3: quotation 7).

Available community support: Both parents and professionals have expressed concerns about transports and accessibility for people with special needs within the community. There has been limited information about transports suitable for children with special needs and barrier free access in shopping malls and community. Both parents and children with special needs have demanding needs for public transports for their daily living. Regardless of types of transports, many parents and professionals in focus group interviews raised their concerns about insufficient transport facilities for disables (Table 3: quotations 8 and 9).

Use of equipment and augmentative devices: There was a lack of information on equipment for children with special needs. The provision of equipment for different disabilities would be essential to help children with special needs to get through basic everyday living. Parents and children mainly have obtained information on equipment from professionals of hospitals and schools, as they were uncertain about the creditability of commercial sources of information. It would be useful to have a list of equipment with description of functions for different disabilities (Table 3: quotation 10).

Paths for transition care of adolescents with special needs: For children who have already left school, the main concerns of the parents and relevant professionals were the challenges in seeking information. Parents often encounter difficulties in caring of children with special needs when they grow up. The provision of residential service for older children and young adults was very insufficient in Hong Kong. On 
Citation: Wong HSW, Li SL, Fu K, Tinsley H, Chow C, et al. (2015) The Importance of Online Resources for Parents of Children with Special Needs in Hong Kong: South China's Experience. J Health Med Informat 6: 192. doi:10.4172/2157-7420.1000192

Information needs for caring of children with special needs Diagnosis, assessment and prognosis of child's medical condition Medical rehabilitation and psychosocial health Education services (include extra-curricular activities) Community support

Use of equipment and augmentative devices

Paths for transition care of adolescents with special needs

Experiences of obtaining and using information

Information from schools and teachers

Information sharing and support from the community

Online information (Internet)

Advantages and challenges of searching and utilizing Internet information

\section{Advantages}

Parent's autonomy in searching information and making enquiries

Useful for decision making

Share experiences via online platforms

\section{Challenges}

Lacking online information searching skills

Risk of misinterpretation of online information

Lacking special functions/features, e.g. word enlargement, sound production

\begin{tabular}{|c|c|c|c|c|}
\hline 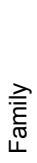 & 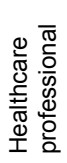 & 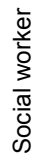 & $\begin{array}{l}\dot{0} \\
\stackrel{0}{0} \\
\frac{0}{0} \\
\text { 山े }\end{array}$ & 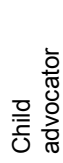 \\
\hline 1 & $x$ & 1 & $x$ & 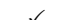 \\
\hline$\checkmark$ & $\checkmark$ & $\checkmark$ & $\checkmark$ & $\checkmark$ \\
\hline$\checkmark$ & $\checkmark$ & $\checkmark$ & $\checkmark$ & $\checkmark$ \\
\hline$\checkmark$ & $\checkmark$ & $\checkmark$ & $\checkmark$ & $\checkmark$ \\
\hline$\checkmark$ & & & $\checkmark$ & $\checkmark$ \\
\hline$\checkmark$ & $\checkmark$ & $\checkmark$ & $\checkmark$ & \\
\hline & & & & \\
\hline$\checkmark$ & & & $\checkmark$ & $\checkmark$ \\
\hline$\checkmark$ & $\checkmark$ & $\checkmark$ & $\checkmark$ & $\checkmark$ \\
\hline$\checkmark$ & $\checkmark$ & $\checkmark$ & $\checkmark$ & $\checkmark$ \\
\hline & & & & \\
\hline & & & & \\
\hline$\checkmark$ & $\checkmark$ & $\checkmark$ & & $\checkmark$ \\
\hline$\checkmark$ & & $\checkmark$ & & \\
\hline$\checkmark$ & & $\checkmark$ & $\checkmark$ & \\
\hline$\checkmark$ & & $\checkmark$ & $\checkmark$ & \\
\hline$\checkmark$ & $\checkmark$ & $\checkmark$ & $\checkmark$ & $\checkmark$ \\
\hline$\checkmark$ & & & $\checkmark$ & \\
\hline
\end{tabular}

Table 2: Data analysis according to study themes.

\section{Information needs for caring of children with special needs}

Diagnosis, assessment and prognosis of child's medical condition

Quotation 1

"There are strong needs of parents for information on their children's medical conditions as they could make a better plan for the child's future when they have more information in hand. Having a long-term plan could reduce parental anxiety as this informs the parents on what to do next." (Occupation therapist from a non-governmental organization)

Medical rehabilitation-and psychosocial health

"When we go to a private clinic, a number of dentists are needed to restrain my son, so the clinic staff can't really help you. As for the clinic services

Quotation 2 provided by the government, we have no ideas where to find these information." (Parent of a child with mental disability who is also representative of a non-government organization)

Quotation 3 "In addition to the pathology, parents also want to know more about their children's psychological health but the information is not so readily available." (Aunt of a child with hearing loss)

"It would be great if more information provided about handling children who are emotionally unbalanced and/or have behavioral problems." (Social worker from a non-government organization) Education services (include extra-curricular activities)

"Parents usually want to find out more about mainstream schools. They would like to know whether mainstream schools enroll special needs children, since which year they start taking students, how many students have special needs, schools' reputation, would teaching being conducted in small classes?" (Educator from a volunteer service association)

"Parents usually told us that their children were still waiting for placement into early training centers, at the time when they were studying kindergarten,

Quotation 6 the waiting queue is far too long. A very common question asked by parents - what else can I do during this period of waiting?" (Social worker serving parents of children with learning disabilities)

Q Parents often ask about information on extra-curricular activities, for example finding a swimming instructor. They want to know if tutors have any experience teaching children with special needs, tuition fee, etc. (Educator from a volunteer service association) Community support

"Regarding transports, it is actually very difficult for students with special needs to get around using buses or MTR [Mass Transit Railway], in particular for those who are in wheelchairs. Waiting for buses is troublesome too: what time will there be a bus installed with a lowered platform? Perhaps, only 2 out of 10 buses that have this facility and there are no information on the schedule of these buses." (Educator from a special school serving children with physical disabilities)

"Shopping malls may have slopes for wheelchairs, but when arrived at the doors, I have to either push or pull them. Otherwise, I have to seek help

Quotation $9 \quad$ from security staff." (Parent of a child with cerebral palsy) Use of equipment and augmentative devices

"Most of the information that I got were provided by the hospital or school, these information cannot be found online. For example, the information on wheelchairs that I got was provided by professionals from hospitals. It is quite hard for me to find the information from external sources. Even though there is information on the Internet, there are not too many websites which have details about where to purchase the equipment." (Male child advocator with walking disability) 
Citation: Wong HSW, Li SL, Fu K, Tinsley H, Chow C, et al. (2015) The Importance of Online Resources for Parents of Children with Special Needs in Hong Kong: South China's Experience. J Health Med Informat 6: 192. doi:10.4172/2157-7420.1000192

Page 5 of 9

Paths for transition care of adolescents with special needs

$\begin{array}{ll}\text { Quotation } 11 & \begin{array}{l}\text { "Parents were still worrying about their children when they grew older. They worried about children's } \\ \text { (Parent of a child with mental disability who is also a representative of a non-government organization) }\end{array}\end{array}$

$\begin{array}{ll}\text { Quotation } 12 & \text { "Because of insufficient resources, organizations could only provic } \\ \text { from the school." (Educator from a special training organization) }\end{array}$

Experiences of obtaining and using information Information from schools and teachers could not help to retrieve those information. Also, they found it difficult to recommend suitable tutors for children with special needs, as the teachers themselves are not certain who may have relevant experience in special education." (Educator from a special school) Information sharing and support from the community

Quotation $14 \quad$ "Social service groups provide a place for them [parents of children with special needs] to get together. This facilitates information exchange among the parents and helps them to identify appropriate support channels. Social service groups are therefore very important." (Sister of a child with learning disability)

"We, as parents sharing similar experiences, are eager to help parents of newly diagnosed children with special needs by giving them one-toone emotional support and providing relevant information on professional counseling services. As we are all in the same boat, we understand their feelings and our words are even more persuasive than doctors and other professionals." (Parent of a child with Thalassemia who is also a representative of Thalassemia Association)

Quotation 15 Online information (Internet)

"In addition to books and journals, I also use the Internet to browse through local and foreign information about disability, in particular information from well-known organizations." (Parent of a child with mental disability who is also representative of a non-government organization)

"There is just too much information available on the Internet, even if parents can find it that won't necessarily help them. They need professional advice as well as information." (Social worker from a non-government organization serving people with neurological impairments) Advantages and challenges of searching and utilizing Internet information

Advantages: Parent's autonomy in searching information and making enquiries

"Parents in the past tended to use direct hotline services. As computer technologies have become more popular over the recent years, parents often

Quotation 18 make use of the web-based platforms to ask questions and search for answers." (Sister of a child with learning disability who is also representative of a non-government organization)

"The therapist did not understand well our true needs. The information I found [through the Internet] by myself is usually more helpful as it best suits my needs." (Male Child advocator with walking disability)

Advantages: Useful for decision making

"The internet provides us with an easy way to look for answers to our questions regarding our child's future education and health. By performing

Quotation 20 online searches together with my child, I could teach him with practical examples so that he could manage his own life and make decisions himself as he grows up." (Parent of a child with cataracts)

Advantages: Share experiences via online platforms

Quotation $21 \quad$ "Parents often search information online about special schools. Discussion forums are useful for parents to learn from others who also have children studying in special schools." (Parent of a child with autism)

"A discussion forum for parents to leave their thoughts and opinions about school services in special needs would be helpful as it facilitates communication and connection with other parents." (Social worker from a non-governmental organization serving children with autism) Challenges: Lacking online information searching skills

"I have the knowledge and skills to use a computer. Yet, I do not know how to start the search if I need medical, educational, or other disability related information from the Internet." (Parent of a child with cataracts)

"Some parents are lack of computer skills, so they contact us directly because they hardly have experiences on Internet search." (Senior teacher from a special school)

Challenges: Risk of misinterpretation of online information

"Some parents may make the wrong interpretation of cases reported in research papers. They may over-focus on the positive aspects of the report

Quotation $25 \quad$ and neglect the huge effort expended on the patient behind each impressive story. Finally, this would result in parents having a false hope." (Sister of a child with a learning disability

"Professional information on the Internet may be too difficult for parents to understand. I think many parents have their own views/thoughts, if

Quotation $26 \quad$ there's a website which can explain the information in layman terms, maybe they can understand more about their children's situation." (Pediatrician specialized in neurology, developmental pediatrics and neurohabilitation)

"Some organizations provide both private and public services and you have to call them up to ask about these assessments. However in the end the information that they provide over the phone is totally different from the information provided on their websites." (Social worker from a nongovernment organization) Challenges: Lacking special functions/features

"It has been the most difficult task to help students with visual impairment to use the Internet. Our school will purchase a visual audio intelligent

Quotation $28 \quad$ organizer for them, but it's only for using in school, hence they cannot use it at home." (Educator from a Vocational Training Institute)

"The equipment assisted children with special needs for viewing computer is very expensive and cannot be brought outside the school." (Parent of a child with Thalassemia who is also a representative of Thalassemia Association)

Table 3: Relevant quotations to support study themes. 
average, they have to wait 10 to 12 years for a daytime activity center cum hostel vacancy. Parents expressed their concerns about caring their children once they entered young adulthood, as they became bigger and heavier. Both parents and educators expressed needs of information for older children (Table 3: quotations 11 and 12).

\section{Experiences of obtaining and using information}

Information from schools and teachers: Although health and child care related information was obtainable from the special needs schools, parents and professionals in this study felt disappointed with their experience of having teachers with limited knowledge about the care and services available for children with special needs (Table 3: quotation 13). This reflected needs of further training for teachers providing special education services. As parents raised concerns if those teachers have sufficient experience in nurturing or helping their children.

Information sharing and support from the community: Parents treasured the experience of obtaining information from their child's social worker and non-governmental organizations, as they found community resources more reliable and helpful. In particular, parents who shared same concerns about their children could exchange information and learn from each other about caring and service sources. Community social service groups helped parents by giving them a platform to communicate and exchange information with other parents. Child professionals also commented that information not only helps to empower parents as caregivers, but also helps parents to identify "similar others", parents who can mutually support each other (Table 3: quotation 14).

Exchange of information and support from other parents can help to alleviate the stress of the caregiver. A parent of a child with thalassemia explained the importance of communication and support provided by other parents in similar circumstances. Child professionals also agreed on the importance of information that was endorsed by friends and other parents with similar experiences. Parents would crosscheck self-obtained information with those provided by friends, in order to verify information reliability from various organizations (Table 3: quotation 15).

Online information (Internet): Internet is a common source for parents to search information about their children's conditions. Some parents may access not just local information; they also read information from overseas websites, aiming to find out as much information as for their children. Although, variety of information is available online, parents still need professionals' advice to choose suitable service for their children. From the parents' perspective, information originated from well-known organizations is important and considered as more reliable (Table 3: quotations 16 and 17).

\section{Advantages and challenges of searching and utilizing Internet information}

\section{Advantages}

Parent's autonomy in searching information and making enquiries: Advances in information technology have allowed parents to search for web-based resources, such as online forums, which are important channels to communicate on health- and service-related information. In this study, caregivers commented on the benefits of new technologies that aid their search for information (Table 3: quotation 18). The Internet allows access to a large volume of information in instant, parents and children can personalize their searches according to their unique needs. A child advocator with special needs himself regarded this particular feature of the Internet as an advantage over directly asking health practitioners, who usually provided limited and too disease-specific information (Table 3: quotation 19).

Useful for decision making: The present study also looked at the benefits of the vast amount of information on the Internet. Access to this information has made it possible for parents to make decisions by carefully considering and searching the best options for their children. Parents and children searching online together may see it as a valuable experience, which in long run could foster the child's independence and self-care ability (Table 3: quotation 20).

Share experiences via online platforms: Discussion forum was a common channel for parents to share information and experience about children's special needs care and concerns. It is also being considered as a hub of frequently asked questions. Illustrated by quotations below not only parents considered discussion forums as a useful platform to exchange knowledge and information, but professionals such as social worker also agreed it facilitated communication among parents and to share their opinions. (Table 3: quotations 21 and 22).

\section{Challenges}

Lacking online information searching skills: The Internet may not be useful for parents with low eHealth literacy, thus conventional sources of information are still important. A parent gave a description of how difficult it was to use the Internet to search for information. This was also echoed by a senior teacher from a special teacher, reflecting the needs of online searching training would be necessary for parents who were less familiar with the use of Internet (Table 3: quotations 23 and 24).

Risk of misinterpretation of online information: Although a vast amount of information can be accessed on the Internet, it is worth noting that parents and children could differ substantially in their levels of eHealth literacy. Family members in the focus group were concerned with a parent's ability to interpret information properly from web-based resources. Professionals also expressed their concerns on the critical appraisal skills of parents of children with special needs (Table 3: quotations 25 and 26). Parents could be misled by some of the online information, which some may be originated from sources of uncertain creditability. Parents have to appraise the information carefully when selecting relevant assessments, treatments and services for their children (Table 3: quotation 27).

Lacking special functions/features: Children with special needs for example those with vision problems, their use of Internet for information search could be limited without helping aid or special website functions, such as word enlargement and sound production. Regarding the use of the internet, the lack of computer skills is already a limitation for some children with special needs, however those who are more capable still are lacking of resources or equipment to perform computer related tasks (Table 3: quotations 28 and 29).

\section{Discussion}

To the best of our knowledge, this is the first qualitative study in Hong Kong and South China that explores the role and importance of health-related online resources for children with special needs. Our study revealed the need for reliable information to help Chinese parents look after their children with special needs. Besides the advice provided by healthcare professionals, parents obtained supplementary information from various sources. Furthermore, parents benefited from the emotional support of other parents in similar situations. 
This observation is consistent with previous studies that found strong positive effects related to parent-to-parent support [39].

Our study found that resources on the Internet could provide comprehensive information and support to parent and families of children with special needs. Other such studies have reported similar advantages of web-based resources that can help individuals and families cope with their illness-related issues [40-42]. Moreover, because of the relative anonymity of the Internet, searching online resources can protect users from social marginalization and stigmatization that would otherwise make face-to-face contact with professionals or other people uncomfortable $[43,44]$. This is particularly relevant in Chinese communities, where many people have a negative attitude toward those with special needs and disabilities. Parents can overcome their hesitancy in seeking help by searching for information online [45].

\section{Drive to seek information}

The present study found that looking for information online gave parents a sense of responsibility because they could understand the condition better and take a more proactive role in raising their children with special needs. Parents could tailor their searches on the Internet for information specific to them and be kept up-todate. Furthermore, as they became more knowledgeable about their children's conditions, they would grow in confidence to be able to provide the best possible care. The nature of the Internet allows some parents to act as information providers by sharing their knowledge and experiences, which could benefit new or less experienced parents in making decisions about caring for their child. Taking advantage of the Internet's almost universal accessibility, parents from around the world can come together to form an online community that can provide a much needed support structure and instill an important sense of belonging to parents caring for children with special needs who may feel isolated.

\section{Information sharing among parents}

Our study showed that parents had a strong tendency to look for additional information supplementary to the advice given by healthcare professionals. A study by Fiks et al. [46] on ADHD children found that parents and clinicians had different perspectives on shared decisionmaking in managing children with special needs. Our study indicated that parents wanted as much information as possible; therefore they would seek for additional sources of information from the Internet or from other parents in similar situations. However, parents still need to be advised by professionals, in order to adequately utilize online information about children with special needs.

Advice based on clinician expertise may be different from that of parents' experiential knowledge. Based on Hartzler and Pratt's definition, clinician's expertise is "knowledge gained from professional training and practice", whereas the parent's experiential knowledge is "knowledge accumulated from their everyday experience with the disabled child" [47]. Parents with experiential knowledge can share real-life insights with less experienced parents of children with special needs, giving them important information that clinicians often fail to offer. Interaction with other parents also provides companionship during difficult times relieving stress and enhancing the well-being of parents and the family [48]. This notion is consistent with our finding that parent-to-parent support was important not only for the exchange of information but also in helping with the emotional well-being of parents. Other studies have reported that interacting with "similar others" had benefits for the mental health of parents of children with special needs $[17,25,39]$. Our study found that community organizations often provided the connection among parents. Websites with discussion forums could also serve as a useful platform for parents to exchange information and opinions, which helps to build mutual support networks among parents.

\section{Use of the Internet and health equity}

The Internet gives almost universal access to a vast amount of information at relatively no cost, and it is undoubtedly a useful tool to reduce the knowledge disparity between the poor and the rich. Yet the online experience can vary widely among individuals from different backgrounds, as reflected by the concern of parents in our study. The digital divide among the parents in this study might be related to variations in their eHealth literacy, a phenomenon that can be found to persist in most parts of the world including Hong Kong [49-51]. Hong Kong is a Chinese city with widening socioeconomic disparity reflected in its Gini coefficient, which is the highest among developed societies [52]. Previous studies have identified age, income and educational level as the most discriminating factors among those who search for online health information [53]. Privileged groups and highly-educated people appear to benefit more from online health information resources than those from disadvantaged families, which include the majority of children with special needs [21,54]. Our study also found the parents and professionals showed major concerns on the difficulties in searching for reliable information and the risk of misinterpretation of information obtained through the Internet. According to previous study on the use of Internet for health promotion, disadvantaged families may be particularly vulnerable to encounter unreliable information or incorrectly interpret the information obtained online [55]. To enable parents of children with special needs to benefit from online information and to bridge this digital divide, the eHealth literacy of parents should be improved and trustworthy credible online healthinformation portals should be established.

\section{Limitations}

In this study, focus group interviews conducted on parents and professionals in relevant fields were used to explore health information seeking and media use among parents of children with special needs. The design and qualitative nature of the study make it difficult to quantify the findings and draw definite conclusions based on the results because the participants in the different groups were from different backgrounds. Although non-parental groups were included as indirect informants to help interpret parents' experiences from multiple perspectives, this approach nevertheless results in bias. In the family focus group, 10 family members of children with special needs were interviewed, including 7 parents, 2 elder siblings of children with learning disability, and an aunt of a child with hearing loss. Elder siblings and aunt as children's carers may have different interpretations and opinions of health information in comparison to parents. In this focus group, we considered these family members are the key carers, but this also had its limitation as we cannot verify if there's any difference in health information perception between parents and non-parental carers. Therefore, results should be interpreted with caution. Moreover, professional participants outnumbered the parents in this study, so caution should be exercised in distinguishing the actual and perceived experiences of parents. Because the group dynamic varied substantially due to differences in the experiences of parents and professionals, the information obtained from each group differed in terms of quantity and quality. Consequently, the synthesized data might not fully represent a balanced representation of the original purposefully selected sample. In addition, this study was conducted in Hong Kong, which is the most developed city in China, so these findings may not be applicable to 
Citation: Wong HSW, Li SL, Fu K, Tinsley H, Chow C, et al. (2015) The Importance of Online Resources for Parents of Children with Special Needs in Hong Kong: South China's Experience. J Health Med Informat 6: 192. doi:10.4172/2157-7420.1000192

other parts of China, such as rural regions. However, we believe the findings reflect all Chinese parents taking into account Chinese culture.

\section{Implications}

Parents need to have a thorough understanding of their children's conditions to be able to make informed decisions. Although the Internet provides a convenient platform for information seeking, not all the information retrievable online is reliable or relevant. A low eHealth literacy or uncertainty in accuracy of online information could make parents anxious or lacking confidence in caring for their child. Professional organizations should actively reach out to those parents with limited Internet skills and provide them with relevant support and training to improve their competence in the use of the Internet [56]. Professionals and information specialists should take into account the issues relating to the digital divide by providing an accessible, up-to-date, trustworthy information website that is easy to understand and contains credible health and service information from multiple online sources. This online platform should be managed and supported by experienced professionals who need to verify the core information and educational materials, so that parents can confidently search for relevant information and advice. Although there are many online forums for parents to network with one another, organized online parent support groups would be useful to share information and provide mutual emotional support among parents of children with special needs. Parents would not only learn about their child's conditions and find relevant support services, but they will also gain confidence and practical skills to help them adjust in their role as a caregiver.

\section{Acknowledgements}

We would like to thank all the participants of the study and the Hong Kong Council of Social Services for providing the venue for the interviews. Special thanks go to Maria Wong, Leona Chan and Chris Lau for their assistance in the interviews.

\section{References}

1. Laskar AR, Gupta VK, Kumar D, Sharma N, Singh MM (2010) Psychosocial effect and economic burden on parents of children with locomotor disability. Indian J Pediatr 77: 529-533.

2. Uskun E, Gundogar D (2010) The levels of stress, depression and anxiety of parents of disabled children in Turkey. Disabil Rehabil 32: 1927-1927.

3. Peer JW, Hillman SB (2012) The mediating impact of coping style on stress perception for parents of individuals with intellectual disabilities. J Intellect Disabil 16: 45-59.

4. Lach LM, Kohen DE, Garner RE, Brehaut JC, Miller AR, et al. (2009) The health and psychosocial functioning of caregivers of children with neurodevelopmental disorders. Disabil Rehabil 31: 607-618.

5. Hussain A, Juyal I (2007) Stress appraisal and coping strategies among parents of physically challenged children. J Indian Acad Appl Psychol 33: 179-82.

6. Abasiubong F, Obembe A, Ekpo M (2006) A controlled study of anxiety and depression in mothers of children with learning disability in Lagos, Nigeria. Niger J Med 15: 124-127.

7. Palmer M, Nguyen T, Neeman T, Berry H, Hull T, et al. (2011) Health care utilization, cost burden and coping strategies by disability status: an analysis of the Viet Nam National Health Survey. Int J Health Plann Manage 26: e151-168.

8. Xiong N, Yang L, Yu Y, Hou J, Li J, et al. (2011) Investigation of raising burden of children with autism, physical disability and mental disability in China. Res Dev Disabil 32: 306-311.

9. Wei X, Yu JW (2012) The concurrent and longitudinal effects of child disability types and health on family experiences. Matern Child Health J 16: 100-108.

10. Tam SF, Cheng AW (2005) Self-concepts of parents with a child of school age with a severe intellectual disability. J Intellect Disabil 9: 253-268.
11. Todd S, Jones S (2003) 'Mum's the Word!': Maternal Accounts of Dealings with the Professional World. Journal of Applied Research in Intellectual Disabilities 16: $229-44$.

12. Rahi JS, Manaras I, Tuomainen $\mathrm{H}$, Hundt GL (2004) Meeting the needs of parents around the time of diagnosis of disability among their children: evaluation of a novel program for information, support, and liaison by key workers. Pediatrics 114: e477-e482.

13. Rahi JS, Manaras I, Tuomainen H, Lewando Hundt G (2005) Health services experiences of parents of recently diagnosed visually impaired children. $\mathrm{Br} \mathrm{J}$ Ophthalmol 89: 213-218.

14. Starke M, Möller A (2002) Parents' needs for knowledge concerning the medical diagnosis of their children. J Child Health Care 6: 245-257.

15. Huang YP, St John W, Tsai SW, Chen HJ (2011) Taiwanese Fathers' Experiences of Having Their Child Diagnosed With a Developmental Disability. J Nurs Res 19: 239-249.

16. Case DO, Andrews JE, Johnson JD, Allard SL (2005) Avoiding versus seeking: the relationship of information seeking to avoidance, blunting, coping dissonance, and related concepts. Journal of the Medical Library Association 93: 353

17. Mak WW, Ho GS (2007) Caregiving perceptions of Chinese mothers of children with intellectual disability in Hong Kong. Journal of Applied Research in Intellectual Disabilities 20: 145-156.

18. Suggs LS (2006) A 10-year retrospective of research in new technologies for health communication. J Health Commun 11: 61-74.

19. Thackeray R, Neiger BL, Hanson CL, McKenzie JF (2008) Enhancing promotional strategies within social marketing programs: use of Web 2.0 social media. Health Promot Pract 9: 338-343.

20. Pleace N, Burrows R, Loader B, Nettleton S, Muncer S (2001) The safety net? Some reflections on the emergence of computer-mediated self-help and social support. In: Keeble L, Loader B (Eds) Community Informatics: Shaping Computer-Mediated Social Relations. London: Routledge 71-85.

21. Blackburn C, Read J (2005) Using the Internet? The experiences of parents of disabled children. Child Care Health Dev 31: 507-515.

22. Plantin L, Daneback K (2009) Parenthood, information and support on the internet. A literature review of research on parents and professionals online. BMC Fam Pract 10: 34

23. Goldman RD, Macpherson A (2006) Internet health information use and e-mail access by parents attending a paediatric emergency department. Emerg Med J 23: $345-348$

24. DeLuca JM, Kearney MH, Norton SA, Arnold GL (2012) Internet use by parents of infants with positive newborn screens. J Inherit Metab Dis 35: 879-884.

25. Kerr SM, Mclntosh JB (2000) Coping when a child has a disability: exploring the impact of parent-to-parent support. Child Care Health Dev 26: 309-322.

26. Semere W, Karamanoukian HL, Levitt M, Edwards T, Murero M, et al. (2003) A pediatric surgery study: parent usage of the Internet for medical information. J Pediatr Surg 38: 560-564.

27. Connolly T, Reb J (2012) Toward interactive, Internet-based decision aid for vaccination decisions: Better information alone is not enough. Vaccine 30 : 3813-3818.

28. Sarkar U, Karter AJ, Liu JY, Adler NE, Nguyen R, et al. (2011) Social disparities in internet patient portal use in diabetes: evidence that the digital divide extends beyond access. J Am Med Inform Assoc 18: 318-321.

29. Fast AM, Deibert CM, Hruby GW, Glassberg KI (2013) Evaluating the quality of Internet health resources in pediatric urology. J Pediatr Urol 9: 151-156.

30. Hong Kong Census and Statistics Department (2009) Persons with Disabilities and Chronic Diseases in Hong Kong. Hong Kong.

31. Oprescu F, Campo S, Lowe J, Andsager J, Morcuende JA (2013) Online information exchanges for parents of children with a rare health condition: key findings from an online support community. J Med Internet Res 15: e16.

32. Knapp C, Madden V, Wang H, Sloyer P, Shenkman E (2011) Internet use and eHealth literacy of low-income parents whose children have special health care needs. J Med Internet Res 13: e75.

33. Krueger RA (2009) Focus groups: A practical guide for applied research $5^{\text {th }}$ $($ Edn), California: Sage. 
Citation: Wong HSW, Li SL, Fu K, Tinsley H, Chow C, et al. (2015) The Importance of Online Resources for Parents of Children with Special Needs in Hong Kong: South China's Experience. J Health Med Informat 6: 192. doi:10.4172/2157-7420.1000192

34. Asbury JE (1995) Overview of focus group research. Qualitative health research 5: 414-420.

35. White GE, Thomson AN (1995) Anonymized focus groups as a research tool for health professionals. Qualitative health research 5: 256-261.

36. Vaughn SR, Schumm JS, Sinagub JM (1996) Focus group interviews in education and psychology, California: Sage Publications.

37. Krippendorff K (2012) Content analysis: An introduction to its methodology, California: Sage.

38. Kidd PS, Parshall MB (2000) Getting the focus and the group: enhancing analytical rigor in focus group research. Qual Health Res 10: 293-308.

39. Ainbinder JG, Blanchard LW, Singer GH, Sullivan ME, Powers LK, et al. (1998) A qualitative study of parent to parent support for parents of children with special needs. J Pediatr Psychol 23: 99-109.

40. Wangberg S, Andreassen H, Kummervold P, Wynn R, Sørensen T (2009) Use of the internet for health purposes: trends in Norway 2000-2010. Scand J Caring Sci 23: 691-696.

41. Kaufman N (2010) Internet and information technology use in treatment of diabetes. Int J Clin Pract Suppl : 41-46.

42. Yardley L, Joseph J, Michie S, Weal M, Wills G, et al. (2010) Evaluation of a Web-based intervention providing tailored advice for self-management of minor respiratory symptoms: exploratory randomized controlled trial. J Med Internet Res 12: e66.

43. Solomon M, Pistrang N, Barker C (2001) The benefits of mutual support groups for parents of children with disabilities. Am J Community Psychol 29: 113-132.

44. Berger M, Wagner TH, Baker LC (2005) Internet use and stigmatized illness. Soc Sci Med 61: 1821-1827.

45. Siperstein GN, Parker RC, Norins J, Widaman KF (2011) A national study of Chinese youths' attitudes towards students with intellectual disabilities. J Intellect Disabil Res 55: 370-384.
46. Fiks AG, Hughes CC, Gafen A, Guevara JP, Barg FK (2011) Contrasting parents' and pediatricians' perspectives on shared decision-making in ADHD. Pediatrics 127: e188-196.

47. Hartzler A, Pratt W (2011) Managing the personal side of health: how patient expertise differs from the expertise of clinicians. J Med Internet Res 13: e62.

48. Singer GH, Marquis J, Powers LK, Blanchard L, DiVenere N, et al. (1999) A multi-site evaluation of parent to parent programs for parents of children with disabilities. Journal of Early Intervention 22: 217-229.

49. Yan YY (2010) Online health information seeking behavior in Hong Kong: an exploratory study. J Med Syst 34: 147-153.

50. Lustria MLA, Smith SA, Hinnant CC (2011) Exploring digital divides: an examination of eHealth technology use in health information seeking, communication and personal health information management in the USA Health informatics journal 17: 224-243.

51. Wang JY, Bennett K, Probst J (2011) Subdividing the digital divide: differences in internet access and use among rural residents with medical limitations. J Med Internet Res 13: e25.

52. Li T (2014) Servants in their own land. China Daily.

53. Renahy E, Chauvin $P$ (2006) Internet uses for health information seeking: $A$ literature review. Rev Epidemiol Sante Publique 54: 263-275.

54. Kind T, Huang ZJ, Farr D, Pomerantz KL (2005) Internet and computer access and use for health information in an underserved community. Ambul Pediatr 5: 117-121.

55. Korp P (2006) Health on the Internet: implications for health promotion. Health Educ Res 21: 78-86.

56. Enebrink P, Högström J, Forster M, Ghaderi A (2012) Internet-based parent management training: a randomized controlled study. Behav Res Ther 50 240-249.

\section{APPENDIX}

\section{Appendix 1 Interview Guide for Focus Group}

All questions are to be discussed from the perspective of parents of children with special needs.

Information needs for caring of children with special needs:

1. In terms of the day-to-day caring for children with special needs, what sorts of information do parents want?

Experiences of obtaining and using information:

2. How do parents obtain those information? What are the obstacles and difficulties parents encountered in obtaining those information?

3. How do parents utilize those information to facilitate caring for children with special needs? In what way do you find those information useful/not that useful?

All sources of information (both online information and off-line information include those provided by professionals from medical, education and social service sectors and self-help groups) are expected to be discussed during interview. In the situation when interview was skewed towards a limited scope of information source, the moderators are responsible to bring up other sources of information for discussion during the interview. 